\title{
Effect of salbutamol on pulmonary responsiveness in chronic pulmonary allergic inflammation in guinea pigs
}

\section{D.I. Kasahara, A. Perini, F.D.T.Q.S. Lopes, F.M. Arantes-Costa, M.A. Martins and M.P.T. Nunes}

Laboratório de Terapêutica Experimental, Departamento de Clínica Médica, Faculdade de Medicina, Universidade de São Paulo, São Paulo, SP, Brasil

\begin{abstract}
Correspondence
M.A. Martins

Departamento de Clínica Médica

Faculdade de Medicina, USP

Av. Dr. Arnaldo, 455, Sala 1216

01246-903 São Paulo, SP

Brasil

Fax: +55-11-3085-0992

E-mail:mmartins@usp.br

Research supported by FAPESP (Nos. 98/00095-0 and 98/0190-2), CNPq and PRONEX-MCT (0879).
\end{abstract}

Received April 13, 2004 Accepted February 14, 2005

\begin{abstract}
Beta-2-agonists have been widely used by asthmatic subjects to relieve their obstructive symptoms. However, there are reports that continuous use could lead to loss of bronchial protection and exacerbation of asthma symptoms. We evaluated the effect of two regimens of salbutamol administration (twice and five times a week) in a model of chronic airway inflammation in male Hartley guinea pigs (protocol starting weight: $286 \pm 30 \mathrm{~g}$ ) induced by repeated exposures to aerosols of ovalbumin (OVA). After sensitization, guinea pigs were exposed to aerosols of $0.1 \mathrm{mg} / \mathrm{ml}$ salbutamol solution twice a week (OVA + S2x, $\mathrm{N}=7)$ or five times a week $(\mathrm{OVA}+\mathrm{S} 5 \mathrm{x}, \mathrm{N}=8)$. We studied allergenspecific (OVA inhalation time) and -nonspecific (response to methacholine) respiratory system responsiveness. Seventy-two hours after the last OVA challenge, guinea pigs were anesthetized and tracheostomized, respiratory system resistance and elastance were measured and a dose-response curve to inhaled methacholine chloride was obtained. Specific $\mathrm{IgG}_{1}$ was also quantified by the passive cutaneous anaphylactic technique. OVA-sensitized guinea pigs $(\mathrm{N}=8)$ showed reduction of the time of OVA exposure before the onset of respiratory distress, at the 5 th, 6 th and 7 th exposures $(\mathrm{P}<0.001)$. The OVA $+\mathrm{S} 2 \mathrm{x}$ group (but not the OVA $+\mathrm{S} 5 \mathrm{x}$ group) showed a significant increase in OVA inhalation time. There were no significant differences in pulmonary responsiveness to methacholine among the experimental groups. OVA + S2x (but not OVA + S5x) animals showed a decrease in the levels of $\mathrm{IgG}_{1}$-specific anaphylactic antibodies compared to the OVA group $(\mathrm{P}<0.05)$. Our results suggest that, in this experimental model, frequent administration of $\beta_{2}$-agonists results in a loss of some of their protective effects against the allergen.
\end{abstract}

Key words

- Salbutamol

- Methacholine

- Experimental asthma

- Beta-agonist

- Pulmonary responsiveness

\section{Introduction}

$\beta_{2}$-agonists have been widely used by asthmatic subjects to relieve obstructive symptoms. The most frequently used $\beta_{2}$-agonists are rapid-acting and include salbuta- mol, terbutaline and fenoterol. These drugs act by binding to $\beta_{2}$-adrenergic receptors and this interaction stimulates adenyl cyclase and promotes an increase in intracellular cAMP. This reduces intracellular calcium, promotes activation of phosphokinase A and phospho- 
rylation of some proteins such as myosin light chain, resulting in relaxation of airway smooth muscle (1).

Many physicians are concerned about the misuse of these bronchodilators because of their paradoxical effects. It has been suggested that regular use of $\beta_{2}$-agonists increases airway responsiveness to allergen challenge and promotes tolerance to their bronchodilator effects, resulting in a loss of bronchial protection against allergens, possibly exacerbating asthma symptoms (2-8).

However, there is evidence of some $\beta_{2^{-}}$ agonist anti-inflammatory activity. Clinical and experimental studies have demonstrated a reduction in inflammatory cells obtained in bronchoalveolar lavage (9) and inhibition of allergy-like effects (10). This anti-inflammatory response is secondary to a negative feedback on T lymphocytes, eosinophils and neutrophils (11). Moreover, the association of $\beta_{2}$-agonists and corticosteroids reduces the inflammatory cell influx in the bronchoalveolar lavage (12), improving asthma symptoms.

In some clinical studies a regular regimen of high doses of $\beta_{2}$-agonists resulted in a fall in forced expiratory volume in $1 \mathrm{~s}$ with an increase in eosinophilic cationic protein levels and eosinophil recruitment $(13,14)$. This increase in airway inflammation may contribute to the worsening of pulmonary function and asthma severity. These side effects were observed four weeks after a regular salbutamol regimen and were reversed by corticosteroid treatment (15). In addition, some investigators have observed tolerance to bronchodilator effects promoted by the use of short-acting $\beta_{2}$-agonists (4-8).

In view of conflicting evidence suggesting that regular use of $\beta_{2}$-agonists can either improve or worsen airway inflammation and hyperresponsiveness, we compared two regimens of $\beta_{2}$-agonist administration in an experimental model of chronic allergic airway inflammation in guinea pigs. We determined the effects of two regimens of salbutamol administration (twice and five times a week) on the acute response to the allergen, the pulmonary responsiveness to methacholine and the development of specific anaphylactic antibodies.

\section{Material and Methods}

All guinea pigs received humane care in compliance with the "Principles of Laboratory Animal Care" published by the National Institutes of Health (NIH publication 86-23, revised 1985). The study was approved by the Institutional Ethics Committee of the School of Medicine of the University of São Paulo.

Sensitization of male Hartley guinea pigs weighing 250 to $350 \mathrm{~g}$, maintained under controlled environmental conditions and with ovalbumin (OVA)-free food and water $a d$ libitum, was performed as previously reported (16). Briefly, the animals were placed in a Plexiglas box $(30 \times 15 \times 20 \mathrm{~cm})$ coupled to an ultrasonic nebulizer (US-1000; ICEL, São Paulo, SP, Brazil) and an OVA aerosol (Grade IV, Sigma, St. Louis, MO, USA) diluted in $0.9 \% \mathrm{NaCl}$ (normal saline) was generated for $15 \mathrm{~min}$ or until respiratory distress occurred. Respiratory distress was defined as the onset of sneezing, coryza, cough, and/or indrawing of the thoracic wall. The observer who made the decision to withdraw the guinea pigs from the inhalation box was not aware of the treatment status of the animal. This protocol was repeated seven times, every $48 \mathrm{~h}$, with increasing concentrations of OVA $(1,2.5$ and $5 \mathrm{mg} / \mathrm{ml}$, respectively, four, two and one times), in order to overcome tolerance. After this sensitization period, guinea pigs were challenged by inhalation of $5 \mathrm{mg} / \mathrm{ml} \mathrm{OVA}$ aerosol once a week for 4 weeks (Figure 1).

\section{Experimental groups}

After the sensitization period, OVA-sensitized guinea pigs were treated by inhala- 
tion of normal saline or of $0.1 \mathrm{mg} / \mathrm{ml} \mathrm{salbu-}$ tamol (Glaxo-Wellcome, São Paulo, SP, Brazil) twice a week or $0.1 \mathrm{mg} / \mathrm{ml}$ salbutamol 5 times a week. The guinea pigs were placed in a Plexiglas box $(30 \times 15 \times 20 \mathrm{~cm})$ coupled to an ultrasonic nebulizer(US-1000; ICEL) and the inhalations lasted $30 \mathrm{~min}$.

OVA-sensitized guinea pigs were divided into 3 groups: OVA + NS $(\mathrm{OVA}+$ normal saline, $\mathrm{N}=8)$, OVA + S2x (OVA + salbutamol twice a week, $\mathrm{N}=7$ ) and OVA + S5x $(\mathrm{OVA}+$ salbutamol five times a week, $\mathrm{N}=$ 8 ). The control groups were: NS + NS (normal saline + normal saline, $\mathrm{N}=7$ ), $\mathrm{NS}+\mathrm{S} 2 \mathrm{x}$ (normal saline + salbutamol twice a week, $\mathrm{N}$ $=8$ ) and NS + S5x (normal saline + salbutamol five times a week, $\mathrm{N}=8$ ).

\section{Measurement of respiratory mechanics}

Guinea pigs were anesthetized with sodium pentobarbital ( $50 \mathrm{mg} / \mathrm{kg}$, ip $)$, tracheostomized and ventilated at 65 breaths $/ \mathrm{min}$ with a tidal volume of $8 \mathrm{ml} / \mathrm{kg}$ using a Harvard 683 ventilator (Harvard Apparatus, South Natick, MA, USA). Tracheal pressure (Ptr) was measured with a differential pressure transducer (DP 45-28-2114; Validyne Corp., Northridge, CA, USA) connected to a side tap in the tracheal cannula. Airflow (V') was measured using a pneumotachograph (Fleisch \#0000, Richmond, VA, USA) attached to the tracheal cannula and to a differential pressure transducer (DP 45-16-2114; Validyne Corp.). Lung volume changes (V) were obtained by electronic integration of $V^{\prime}$. Ptr and $V^{\prime}$ 'signals were registered with a Gould RS 3400 (Cleveland, OH, USA) recorder and sampled at $200 \mathrm{~Hz}$ with an analog-todigital converter (DT2801A; Data Translation, Marlboro, MA, USA) and stored in a microcomputer. Nine to ten respiratory cycles were averaged to provide one data point. Respiratory system resistance (Rrs) and elastance (Ers) were obtained using the equation of motion of the respiratory system, as follows:
$\operatorname{Ptr}(\mathrm{t})=\operatorname{Ers} \cdot \mathrm{V}(\mathrm{t})+\operatorname{Rrs} \cdot \mathrm{V}^{\prime}(\mathrm{t})$,

where $\mathrm{t}$ is time.

\section{Methacholine dose-response curves}

Methacholine chloride (Sigma) was dissolved in normal saline. Increasing concentrations of methacholine $(0.1,0.3,1,3,10$, and $30 \mathrm{mg} / \mathrm{ml}$ ) were delivered by an ultrasonic nebulizer connected to the Harvard 583 ventilator. Each concentration of methacholine chloride was delivered for $1 \mathrm{~min}$ and the interval between two doses was 5 min. Peak values of Ptr and corresponding V' values after each dose of methacholine were recorded.

\section{Passive cutaneous anaphylaxis}

At the end of the determination of the methacholine dose-response curve, blood samples were collected from the right ventricle by cardiac puncture and serum was obtained for the measurement of anaphylactic $\mathrm{IgG}_{1}$. OVA-specific anaphylactic $\mathrm{IgG}_{1}$ and $\mathrm{IgE}$ antibody titers were measured by the passive cutaneous anaphylaxis technique as described by Ovary (17) and modified by Mota and Perini (18). Briefly, guinea-pig serum $\mathrm{IgG}_{1}$ anti-OVA antibodies were de-

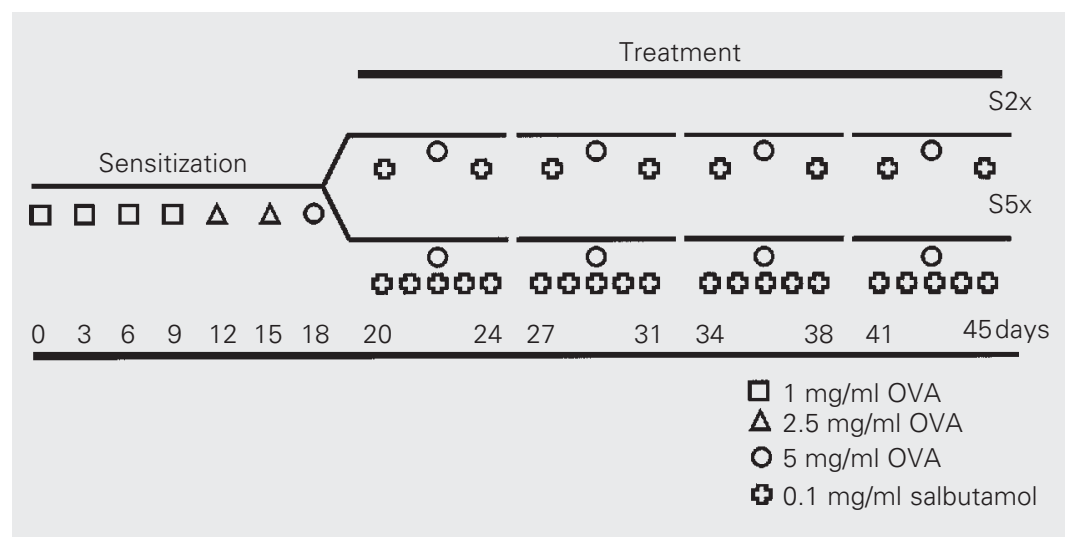

Figure 1. Study design for sensitization to antigen and salbutamol treatment. Guinea pigs were sensitized with aerosols of ovalbumin (OVA) solution for $15 \mathrm{~min}$ or until the development of signs of respiratory distress. On day 20 they started to also receive treatment with aerosols of salbutamol either twice a week (S2x) or five times a week (S5x). 
tected after incubation for $3 \mathrm{~h}$ at $56^{\circ} \mathrm{C}$ to neutralize IgE antibodies. An aliquot of 0.1 $\mathrm{ml}$ of the diluted sample (IgE or $\operatorname{IgG}_{1}$ ) was injected intradermally into a naive guinea pig. After passive sensitization $\left(24 \mathrm{~h} \mathrm{IgG}_{1}\right.$ and $46 \mathrm{~h}$ for $\mathrm{IgE}$ ), these guinea pigs were challenged with intravenous injection of 1 $\mathrm{ml} 0.9 \%$ saline solution containing $1 \mathrm{mg}$ OVA and $10 \mathrm{mg}$ Evans blue dye. One hour

Figure 2. $A$, Time of exposure to ovalbumin (OVA) aerosol until the development of signs of respiratory distress $(\mathrm{N}=8)$. ${ }^{*} \mathrm{P}<$ 0.001 compared to the 4th exposure (two-way ANOVA). All guinea pigs exposed to saline $(\mathrm{N}$ $=7$ ) remained in the inhalation box for $15 \mathrm{~min}$ in all exposures. $B$, Inhalation time corresponding to exposure to $5 \mathrm{mg} / \mathrm{ml}$ OVA aerosol before (left columns) and after (right columns) 4 weeks of treatment with saline $(\mathrm{N}=8)$ or salbutamol twice a week $(\mathrm{S} 2 \mathrm{x}, \mathrm{N}=7)$ or five times a week (S5x, N = 8). ${ }^{*} \mathrm{P}=0.002$ compared to other groups (twoway ANOVA).

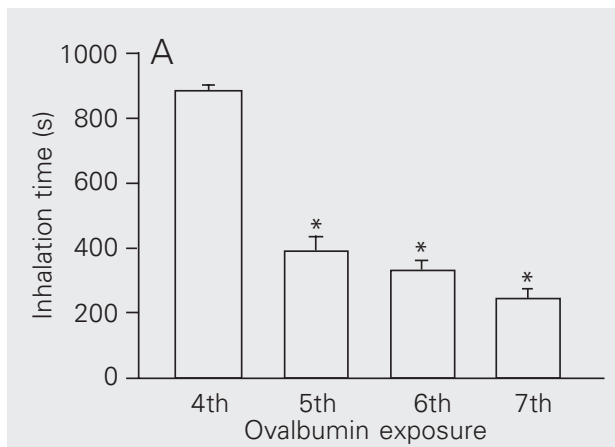

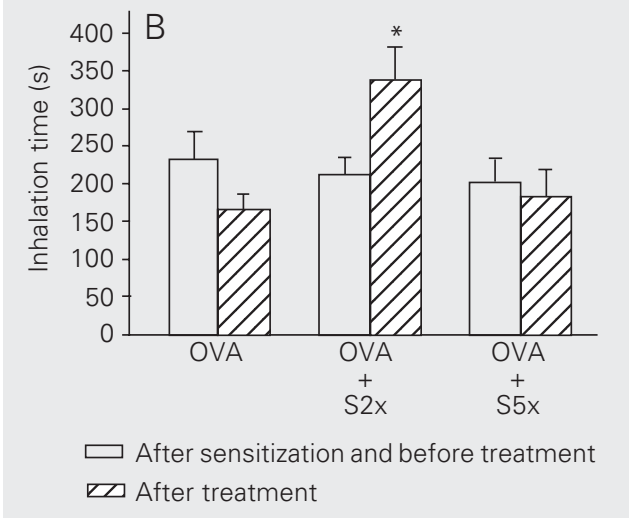

Table 1. Basal (pre-methacholine challenge) respiratory system elastance and resistance.

\begin{tabular}{llll}
\hline $\begin{array}{l}\text { Group } \\
\left.\mathrm{s}^{-1}\right)\end{array}$ & $\mathrm{N}$ & $\mathrm{Ers}\left(\mathrm{cmH}_{2} \mathrm{O} / \mathrm{ml}\right) \operatorname{Rrs}\left(\mathrm{cmH}_{2} \mathrm{O} \mathrm{ml}\right.$ & -1 \\
& & & \\
$\mathrm{NS}+\mathrm{NS}$ & 7 & $1.61 \pm 0.51$ & $0.22 \pm 0.05$ \\
$\mathrm{NS}+\mathrm{S} 5 \mathrm{x}$ & 8 & $1.27 \pm 0.19$ & $0.19 \pm 0.04$ \\
$\mathrm{NS}+\mathrm{S} 2 \mathrm{x}$ & 8 & $1.51 \pm 0.50$ & $0.23 \pm 0.08$ \\
OVA + NS & 8 & $1.51 \pm 0.35$ & $0.24 \pm 0.07$ \\
OVA + S2x & 7 & $1.49 \pm 0.35$ & $0.28 \pm 0.15$ \\
OVA + S5x & 8 & $1.78 \pm 1.29$ & $0.23 \pm 0.03$
\end{tabular}

Data are reported as means \pm SD. Guinea pigs were exposed to either normal saline (NS) or ovalbumin (OVA) aerosols (first column) and were treated with NS or salbutamol five times per week (S5x) or twice a week (S2x; second column). Ers = respiratory system elastance; $\operatorname{Rrs}=$ respiratory system resistance. later, guinea pigs were sacrificed and the diameter of the blue spots on the inner surface of the flayed skin was measured. The passive cutaneous anaphylaxis titer was taken to be the highest dilution that presented a blue spot at least $10 \mathrm{~mm}$ in diameter.

\section{Statistical analysis}

Two-way repeated measure analysis of variance (experimental group and exposure to the allergen) for one repeated factor (exposure to the allergen) was used to study inhalation time. One-way analysis of variance was used to compare Rrs and Ers values, and the indexes of pulmonary responsiveness to methacholine. To isolate the group or groups that differed from the others a multiple comparison procedure (Tukey test) was used. $\mathrm{P}$ values less than 0.05 were considered to be significant.

\section{Results}

\section{Exposure to ovalbumin (inhalation time)}

During the first three inhalations there were no signs of respiratory distress in any of the guinea pigs that received aerosols of OVA solution. Respiratory symptoms occurred during inhalations 5, 6 and 7. Figure $2 \mathrm{~A}$ shows the inhalation time (time that guinea pigs remained in the inhalation box without respiratory symptoms) of the guinea pigs that received OVA aerosols but not salbutamol. The inhalation time decreased in the 5th, 6th, and 7th inhalations compared to the first four inhalations $(\mathrm{P}<0.001)$, showing sensitization to OVA.

The time that the guinea pigs remained in the inhalation box during exposure to OVA aerosol until the development of any sign of respiratory distress was also recorded at the end of the sensitization period ( 2 weeks) and at the end of the treatment period, when the guinea pigs were exposed to either saline or salbutamol aerosols (4 weeks). The inhala- 
tion time was similar for all groups that received OVA aerosols at the end of the sensitization period (Figure 2B). However, at the end of the treatment period, the group of OVA-sensitized guinea pigs that received aerosols of salbutamol twice a week remained in the inhalation box before the beginning of respiratory symptoms for a significantly longer time than the other three groups $(\mathrm{P}=$ 0.002). In contrast, the group of OVA-sensitized guinea pigs that received salbutamol treatment five times per week did not show a significant difference in inhalation time compared to OVA-sensitized guinea pigs that did not receive salbutamol.

\section{Respiratory mechanics and methacholine challenge}

Baseline (immediately before the doseresponse curve to aerosolized methacholine) values of Ers and Rrs are shown in Table 1. No statistically significant differences were observed among the groups studied.

The concentration of methacholine chloride that resulted in $50 \%$ of maximal response was calculated for both Rrs and Ers. We did not observe any significant effect of salbutamol treatment on the values of $50 \%$ of maximal response for either Rrs or Ers. Salbutamol treatment either twice a week or daily did not result in a significant modification of the maximal respiratory system mechanical changes induced by methacholine aerosol.

\section{Anaphylactic IgE and $\operatorname{lgG}_{1}$ antibodies}

No antigen-specific anaphylactic IgE antibodies were observed in any experimental group. However, guinea pigs treated with salbutamol twice a week showed lower titers of $\mathrm{IgG}_{1}$-specific antibodies (1:240) compared to guinea pigs sensitized with OVA that received no treatment with salbutamol (1:960). In contrast, guinea pigs that received salbutamol five times per week showed $\mathrm{IgG}_{1^{-}}$ specific antibody titers similar to those of sensitized guinea pigs not treated with salbutamol (1:960) (5 animals per group, $\mathrm{P}<$ $0.05)$.

\section{Discussion}

To study the possible effects of prolonged $\beta_{2}$-agonist treatment on airway responsiveness to allergens and to bronchoconstrictors, we used an experimental model of chronic airway inflammation and tested two regimens of salbutamol administration: twice a week to simulate an intermittent administration and five times a week to simulate a more continuous use. Few experimental studies have investigated the effects of $\beta_{2}$-agonists on the inflammatory response in animal models of chronic allergic inflammation. The inhalation of environmental allergens is a major mechanism of asthma, and experimental models with allergen-induced chronic airway inflammation are probably more relevant to the study of the mechanisms of human asthma than models with a single challenge (19). In a previous study, we assessed the effects of airway inflammation induced by repeated OVA aerosol exposures in guinea pigs (16). Maximal Rrs and Ers values after antigen challenge were higher in guinea pigs submitted to repeated antigen exposures than in controls (saline exposure), showing the presence of an allergen-specific response. There was an intense peribronchial edema and an increase in lymphocytes and eosinophils both in bronchoalveolar lavage fluid and distal airways in OVA-sensitized guinea-pigs. Immunohistochemistry with monoclonal antibodies revealed that most mononuclear cells present on the airway walls were $\mathrm{CD} 4+\mathrm{T}$ cells (16).

In the present study, we used the same experimental model of chronic airway inflammation in guinea pigs induced by repeated exposures to aerosolized OVA (16) to evaluate the effects of two regimens of administration of a short-acting $\beta_{2}$-agonist 
(salbutamol). We started the treatment with salbutamol two weeks after the beginning of the exposures to OVA to avoid effects of salbutamol on sensitization to OVA. Although this experimental model results in airway inflammation, there is no significant change in basal respiratory mechanics. In fact, we did not observe any significant difference in Ers or Rrs among the experimental groups at the end of the experimental protocol, when the guinea pigs were anesthetized and mechanically ventilated (Table 1).

We evaluated the effects of salbutamol on pulmonary responsiveness to both OVA (specific) and methacholine (nonspecific). To assess pulmonary responsiveness to OVA we computed the time that the guinea pig remained exposed to the OVA aerosol until the onset of respiratory distress. We observed that, since the 5th inhalation of OVA, the guinea pigs were able to remain in the box less time than guinea pigs that received aerosols of normal saline (Figure 2A), indicating the presence of sensitization and the development of an early phase response to the allergen. Interestingly, we could observe a protection against the early response to inhaled OVA only in the group of guinea pigs that received salbutamol twice a week (Figure 2B). This attenuation in the acute response to the allergen was not observed in the guinea pigs that received salbutamol five times per week, suggesting that, in this experimental model, the daily use of a $\beta_{2^{-}}$ agonist results in a loss of this protective effect against allergen challenge in sensitized guinea pigs.

To study the effect of salbutamol treatment on the pulmonary responsiveness to methacholine we performed dose-response curves to inhaled methacholine chloride and to compare the experimental groups we calculated, for each animal, the dose of methacholine that resulted in $50 \%$ of maximal changes of Rrs and Ers, according to Hulbert et al. (20). We also calculated the maximal values of Rrs and Ers induced by methacholine administration for each guinea pig. We did not observe any significant effect of salbutamol treatment in either $50 \%$ of maximal changes or in the maximal response to methacholine.

In the experimental model of airway inflammation induced by repeated exposures to inhaled OVA there is production of $\operatorname{IgG}_{1}$ anaphylactic antibodies but not of $\operatorname{IgE}$ $(18,21)$. In fact, passive cutaneous anaphylaxis analysis revealed that guinea pigs exposed to OVA but not to salbutamol (OVA + NS group) did not show specific anaphylactic IgE antibodies but showed high titers of $\mathrm{IgG}_{1}$ antibodies (a response observed even at 1:960 dilution). Treatment with salbutamol five times per week did not influence this response. However, treatment with salbutamol only twice a week resulted in significantly lower values of $\operatorname{IgG}_{1}$ antibodies (1:240).

In guinea pigs the regular use of $\beta_{2}$-agonists induces airway narrowing and an increase in smooth muscle contractility (19). This treatment can also contribute to the increase of bronchial responsiveness (9) due to the reduction of constitutive adrenergic effects by either receptor down-regulation and/or decrease of receptor turnover, both reducing the receptor density on the cell surface. In the present study, we have shown that only salbutamol administered twice a week (but not five times a week) resulted in an attenuation of the early pulmonary response to the antigen.

The effect of $\beta_{2}$-agonists on bronchial responsiveness remains controversial. Sears et al. (4) observed a small although significant increase in bronchial responsiveness in patients treated with a regular regimen of fenoterol when compared to patients receiving fenoterol under a demand regimen. In contrast, Chapman et al. (5) reported a better asthma control when salbutamol was used in a regular manner compared to use only as needed. Some investigators observed that a 
single dose of $\beta_{2}$-agonist protects the patients against a wide variety of bronchoconstrictor stimuli, independently of bronchodilator activity $(8,22)$.

A slight anti-inflammatory activity of $\beta_{2^{-}}$ agonists has been suggested, possibly due to intracellular increase of cAMP generated by the activation of adenyl cyclase in CD4+ lymphocytes, eosinophils and neutrophils, reducing the release of inflammatory mediators from these cells $(10,23,24)$. In our experimental model, we observed that the administration of salbutamol twice a week resulted in lower levels of $\operatorname{IgG}_{1}$-specific anaphylactic antibodies and this effect of salbutamol was not observed in the group of guin- ea pigs that received salbutamol five times a week.

We demonstrated here that in guinea pigs with chronic allergic pulmonary inflammation, administration of salbutamol twice a week resulted in lower levels of anaphylactic antibodies and an attenuation in the early response to the allergen. These effects were not observed when salbutamol was administered five times a week. However, neither regimen changed pulmonary responsiveness to methacholine. Our results suggest that, in this experimental model, a more frequent administration of $\beta_{2}$-agonists results in a loss of some of their protective effects against the allergen.

\section{References}

1. Hall IP \& Tattersfield AE (1998). ß-Adrenoceptor agonist. In: Barnes PJ, Rodger IW \& Thomson NC (Editors), Asthma. Basic Mechanisms and Clinical Management. 3rd edn. Academic Press, San Diego, CA, USA, 651-678.

2. Cockcroft DW, McParland CP, Britto SA, Swystun VA \& Rutherford BC (1993). Regular inhaled salbutamol and airway responsiveness to allergen. Lancet, 342: 833-837.

3. Cockcroft DW, O'Byrne PM, Swystun VA \& Bhagat R (1995). Regular use of inhaled albuterol and the allergen-induced late asthmatic response. Journal of Allergy and Clinical Immunology, 96: 44-49.

4. Sears MR, Taylor DR, Print CG, Lake DC, Li Q, Flannery EM, Yates DM, Lucas DM, Lucas MK \& Herbison GP (1990). Regular inhaled beta-agonist treatment in bronchial asthma. Lancet, 336: 13911396.

5. Chapman KR, Kesten S \& Szalai JP (1994). Regular vs as-needed salbutamol in asthma control. Lancet, 343: 1379-1382.

6. Wang Z, Walker BAM, Weir TD, Yarema MC, Roberts CR, Okazawa M, Paré PD \& Bai TR (1995). Effect of chronic antigen and ß2agonist exposure on airway remodeling in guinea pigs. American Journal of Respiratory and Critical Care Medicine, 152: 2097-2104.

7. Hancox RJ, Aldridge RE, Cowan JO, Flannery EM, Herbison GP, McLachlan CR, Town GI \& Taylor DR (1999). Tolerance to betaagonist during acute bronchoconstriction. European Respiratory Journal, 14: 283-287.

8. Cheung D, Timmers MC, Zwinderman AH, Bel EH, Dijkman JH \& Sterk PJ (1992). Long-term effects of a long-acting ß2-adrenoceptor agonist, salmeterol, on airway hyperresponsiveness in patients with mild asthma. New England Journal of Medicine, 327: 1198-1203.

9. Sugiyama H, Okada C, Bewtra AK, Hopp RJ \& Townley RG (1992). The effect of formoterol on the late asthmatic phenomena in guinea pigs. Journal of Allergy and Clinical Immunology, 89: 858-866.

10. Petersen LJ \& Skov PS (1999). The effect of salmeterol and salbutamol on mediator release and skin responses in immediate and late phase allergic cutaneous reactions. Inflammation Research, 48: 527-532
11. Twentyman OP, Finnerty JP \& Holgate ST (1991). The inhibitory effect of nebulized albuterol on the early and late asthmatic reactions and increase in airway responsiveness provoked by inhaled allergen in asthma. American Review of Respiratory Disease, 144: 782-787.

12. Gardiner PV, Ward C, Booth $H$, Allinson A, Hendrick DJ \& Walters EH (1994). Effect of eight weeks of treatment with salmeterol on bronchoalveolar lavage inflammatory indices in asthmatics. American Journal of Respiratory and Critical Care Medicine, 150: 10061011.

13. van Schayck CP, Dompeling $E$, van Herwaarden CLA, Folgering $H$, Verbeek ALM, van der Hoogen HJM \& van Weel C (1991). Bronchodilator treatment in moderate asthma or chronic bronchitis: continuous or demand? A randomized controlled study. British Medical Journal, 303: 1426-1431.

14. Gauvreau GM, Jordana M, Watson RM, Cockcroft DW \& O'Byrne PM (1997). Effect of regular inhaled albuterol on allergen-induced late responses and sputum eosinophils in asthmatic subjects. American Journal of Respiratory and Critical Care Medicine, 156: 1738-1745.

15. Holgate ST, Baldwin CJ \& Tattersfield AE (1997). ß-adrenergic agonist resistance in normal human airways. Lancet, 2: 375-377.

16. Tibério IF, Turco GM, Leick-Maldonado EA, Sakae RS, Paiva SO, Warth MPTN, Lapa e Silva JR, Saldiva PH \& Martins MA (1997). Effects of neurokinin depletion on airway inflammation induced by chronic antigen exposure. American Journal of Respiratory and Critical Care Medicine, 155: 1739-1747.

17. Ovary Z (1964). Passive Cutaneous Anaphylaxis. Immunological Methods. Blackwell Scientific Publications, Oxford, 259.

18. Mota I \& Perini A (1970). A heat labile mercaptoethanol susceptible homocytotropic antibody in the guinea pig. Life Sciences, 9 (Part II): 923-930.

19. Wang ZL, Bramley AM, McNamara A, Paré PD \& Bai TR (1994). Chronic fenoterol exposure increases in vivo and in vitro airway responses in guinea pigs. American Journal of Respiratory and 
Critical Care Medicine, 149: 960-965.

20. Hulbert WC, McLean T, Wiggs B, Pare PD \& Hogg JC (1995). Histamine dose-response curves in guinea-pigs. Journal of Applied Physiology, 58: 625-634.

21. Warth MPTN, Maldonado EAL, Fernezlian SM, Leme AS, Perini A Saldiva PHN \& Martins MA (1995). Neurokinin depletion attenuates pulmonary changes induced by antigen challenge in sensitized guinea pigs. American Journal of Physiology, 268: L781-L788.

22. Fadden Jr ER \& Gilbert IA (1992). Asthma. New England Journal of
Medicine, 327: 1928-1937

23. Panina-Bordignon $P$, Mazzeo D, Di Lucia P, D'Ambrosio D, Lang R, Fabbri L, Self C \& Sinigaglia F (1997). B2-Agonist prevent Th1 development by selective inhibition of interleukin 12. Journal of Clinical Investigation, 100: 1513-1519.

24. Farmar P \& Pugin J (2000). B-adrenergic agonists exert their "antiinflammatory" effects in monocytic cells through the I $\mathrm{kB} / \mathrm{NF} \kappa \mathrm{B}$ pathway. American Journal of Physiology, 279: L675-L682. 